\title{
The Evolution Of Smartcard And EMV Migration In Bahrain
}

Adel Al-Alawi, (E-mail: alalawi@itc.uob.bh), University of Bahrain Nadia Al-Qurashi, (E-mail: Nadia_Al-Qurashi@Bapco.net), University of Bahrain

\begin{abstract}
Within the improvement of Information Technology era, many business enterprises, academia institutions and banks in various regions around the world are enthusiastic and looking into the future by producing an all-in-one smart card with Europay, MasterCard and Visa (EMV) protocols for their employees, students or customers. This smart card can be used in different fields such as ID card, debit/credit card, transportations, healthcare, communication networks, loyalty, etc., with high level of security. This paper gives the reader an overview of the evolution of smart card and the important benefits derived over the existing traditional magnetic stripe card. The paper aims to study the following five key elements: Importance of EMV, EMV Implementation in Bahrain, Obstacles and Constraints, Customer Satisfaction, and EMV Future in Bahrain. The results of the study reveals that Bahrain is on its approach towards the EMV migration and will definitely be ready for rollout in the coming few years. It was also demonstrated that even though adopting EMV smart card technology may cost the organization a lot, it would be on the other hand very beneficial to them in many different aspects. Furthermore, it was provided that moving toward smart card in general will differentiate Bahrain and will put her among the leader. This paper can be used as a basis for further researches to improve specific aspects of the evolution of smart card and EMV Migration in the Kingdom of Bahrain or elsewhere. It will also provide a useful input for other local banks and/or organizations that have not proceed towards smart card adaptation yet.
\end{abstract}

\section{Introduction}

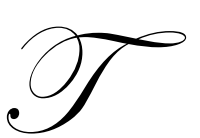

he idea of smart card has been evolved for more than twenty years, with a very basic application mainly used for payphone system (Petri, 2000). However, with the rapid advantages of technology world environment and the necessity of fast data transfer, smart card has become a critical issue in different government, financial and industrial sectors.

It has been said that smart cards will become in the near future as important as computers are today. Smart cards could prove their quite usefulness worldwide as a transaction, authorization and identification medium as in European countries. Smart cards could replace many other useless cards user carries around in his wallet, such as credit cards, debit cards, club membership cards, driving licenses, and other things like cash and even family photos.

Because there are a variety of smart card applications, several standards were defined by the International Organization for Standardization (ISO) for the operation of each different application. The price of a smart card depends upon its capacity. The average price for all microprocessor cards is $\$ 3.79$ each, whereas, the average price for a memory card is estimated at 47 cents (Framer and Tonac, 2003).The reasons for the growth of using smart cards are mainly their portability and security characteristics, and also the user need of having smaller and smaller devises that enable him to carry his data anywhere.

Smart cards are perfect solutions for e-commerce transactions. They actually offer more security and confidentiality than any other financial information or transaction storage vehicles. They are very safe for storing valuable information such as private keys, account numbers, passwords, or personal information, i.e. performing a public key or private key encryption. Smart cards have computational or processing power to provide greater security, allowing verification for the cardholder. There are two verification methods can be done by the smart cards, entering a 
PIN and biometrics. Smart cards help business evolve and expand their product and services in a changing global marketplace. The scope of smart card usage has expanded each year to include applications in a variety of markets and disciplines.

Businesses, the governments and healthcare organizations continue to move towards storing and releasing information via networks, Intranets, extranets and the Internet. These organizations are turning to smart cards to make this information readily available to those who need it, while at the same time protecting the privacy of individuals and keeping their informational assets safe from hacking and other unwanted intrusions.

\section{THE PROBLEM AND ITS SETTING}

The concept of multi-applications smart card with EMV specification has widely been focused in various regions around the world such as Europe, and yet there are many interesting developments taking place in GCC in general, and in Bahrain in particular which have received very little attention. Moreover, the scarcity of academic research on smart card and EMV Implementation in our Kingdom prompted calls for precise research and empirical studies examining the value of smart card with EMV standards. Therefore, this study emerged as a response to the call by describing few relatively best practitioners in the related field of smart card in the Kingdom of Bahrain. Thus, the main objective of this study is to examine the importance of smart cards adaptation and EMV migration in Bahrain, customer satisfaction, EMV Future in Bahrain, and investigate the problems facing the banks/organizations who are directly involved in EMV program.

\section{THE IMPORTANCE OF THE STUDY}

The importance of smart card with EMV standards will rapidly increase over the few coming years as users obtain powerful operations with multi-applications, and businesses use information more and more for secured data storage, and decision-making as a strategic weapon.

Due to the shortage in the literature about smart card and EMV specifications in Bahrain, it seems that conducting this study shall add to the literature something of an academic and practical value. Therefore, this study will examine the necessity of using smart card and draw the attention of the reader towards the great potential that can be gained from applying smart card.

\section{LIMITATION AND DIFFICULTIES}

Identifying a technology that is a recent initiative is a bit difficult in a market, which is continually changing every day. Therefore, the selection took into consideration the introduction of such advance technology in Bahrain because it is one of the realized important competency tools needed for banks and service providers to compete and differentiate among the others.

In addition, some of the technical web sites that contain recent valuable reports and research papers could not be accessed, as they require fee subscription. Whereas, Google and AltaVista search engines were very helpful and extensively used to obtain most of the literature review of the assignment report. Unfortunately, it would be better to survey the local market in Bahrain to understand the real impact of this selected topic on customers and cardholders, but it could not be carried due to the emergence of this new technology and the long life of adaptation.

\section{REPORT STRUCTURE}

The report is basically divided into six chapters. Chapter one provides the reader with a brief background on smart card evolutions. It discusses the research problem and its setting, the importance of the study, limitation and difficulties, and the structure of the report. Chapter two includes a literature survey of academic journals, research papers and business articles that discuss and studied the subject of smart card and EMV specifications in different perspectives. Chapter three illustrates the survey methodology were used to collect the primary and secondary data. This chapter also describes the research framework and constructs, sample selection, research instruments; and, data 
collection and gathering. Chapter four covers the findings of the interviews conducted, analysis of the results in comparison with the literatures and key elements in order to reach to a satisfactory conclusion. Chapter five involves the main principal conclusions drawn from the interviews conducted. Chapter six offers recommendations to avoid any unsatisfactory situation, and to reach a successful system, and well-satisfied customer.

\section{LITERATURE REVIEW: WHAT IS SMART CARD?}

A smart card is a unique, small portable personal object with and embedded microprocessor chip - called an integrated circuit chip (ICC) - which provides memory storage and processing power that easily combines secure identification and authentication functions for both the physical and digital worlds. The shape of the smart card looks like any other normal credit card, with totally different applications. A smart card can act as an electronic wallet (epurse) and this feature differentiates the card from the other normal credit card and bankcard functions.

HKUST Cyberspace Center (1998) defined the smart card as a "credit card with a brain on it". This card offers a number of significant benefits to financial institutions, retailers, and cardholders such as security improvement, fraud reduction, manage a growing number of transactions and ensure interoperability of different debit/credit applications.

Framer and Tonac (2003) demonstrated that there are two feasible methods or interfaces of smart card to function, contact and contactless. Contact smart card is very popular in use today's, it is mainly designed to communicate with the card reader by a direct physical contact or insertion. However, contactless smart card operates through a radio frequency (RF) signal. An antenna is embedded inside the card, which enables communication with the reader without physical contact. While a combi card, combines the features of both contact and contactless smart cards with a very high level of security.

Whatever the type is of smart card, the storage capacity of its memory content is much larger than in magnetic stripe card. The total storage capacity of a magnetic stripe card is only 125 bytes, while the typical memory capacity of a smart card could be $16 \mathrm{~KB}, 32 \mathrm{~KB}, 64 \mathrm{~KB}$ and $128 \mathrm{~KB}$. However, $32 \mathrm{~KB}$ memory capacity is currently the most popular (Won, 2003).

The latest advent of smart card is to provide unlimited applications in different fields in our daily life. Thus the multi-applications offered by the smart cards are the following:

- $\quad$ Personal information
- $\quad$ Plectronic purse transactions
- $\quad$ Personal authentication information
- $\quad$ Personal finance transactions
- $\quad$ Lealth-care data
Loyalty program information

Smart card can work both, online and off-line rather than traditional magnetic-stripe card. They are delivering superior off-line security, reducing telecommunication costs through the use of off-line authorizations, offering greater capacity for storing information on cardholder preferences and buying habits, and providing additional speed and functionality.

\section{WHAT IS EMV STANDARDS?}

According to Mosaic Software UK Ltd. (2001) EMV can be defined as "an agreed specification between Europay (E), MasterCard (M) and Visa (V) for the interoperability of smart cards and terminals equipped with smart card readers for debit and credit schemes - Interoperability refers to the objective of ensuring that all EMV terminals at a purely technological level can process all EMV cards". 
Access Keyboards Ltd. (2003) demonstrated that "the objective of the abovementioned leading card associations is to ensure that single terminal and card approval processes are developed at a level in order to allow cross payment system interoperability on global basis through compliance with the EMV specifications".

Thales e-Security Inc. (2004), also illustrated that "the major card associations are setting dates by which regions around the world must have completed migration to EMV cards. Beyond these dates liability for fraudulent transactions will lie with magnetic stripe card issuers or acquirers.

\section{HISTORY OF SMART CARDS}

The origin of smart card began when consumer requirements about convenience and security outpaced the capabilities of magnetic stripe cards. OTI America (2004) and Petri (2003) explored that the development of smart cards in use today's can be traced back to the United States in 1950s when Diners Club the first plastic cards were produced for the payment applications purposes. In 1968, two German inventors - Jurden Dethloff and Helmut Grtrupp applied for the integrated circuit chip (ICC), and the similar application followed in Japan in 1970. However, the modern and successful history of smart cards was in France in early seventies, when they first invented by the pioneer Roland Moreno in 1974. Nowadays, smart cards are re-usable, hold large quantities of data, speed transaction times, identify the cardholder, and provide loyalty benefits. Smart cards from different vendors could also communicate with the host machine using a common set of language, and that is only the beginning of the age of smart cards.

\section{THE KEY PARTICIPATING PARTIES} follows:

Four different parties are involved when consider smart card payments, these parties can be identified as

- The Manufacturer: who creates the cards and develop the necessary software to operate them.

- The card issuer: who is responsible for issuing the cards and making sure that payment system is operating properly.

- $\quad$ The merchant: a person who accepts the payments made by the smart cards.

- The consumer: that gets the smart card from the issuer and makes the purchase transactions at merchants using smart card.

\section{SMART CARD STANDARDS}

Throughout the development history of smart card, various standards have been introduced to define the operation of the technology and promote product interoperability between smart-card manufacturers. In 1987, the International Organization for Standardization (ISO) published ISO 7816 the very first smart card standard. ISO 7816$\mathrm{X}$ is the dominant and interface standard for smart cards consisting of ten sections that detail the physical, electrical, mechanical, and application programming interface. ISO standards enable smart cards to communicate using the same protocols. Petri (2003) disclosed that several standards define the operation of a smart card for various applications, so it is important to understand these standards when selecting a smart card and a reader for a specific application. Any standard designed to facilitate the integration of smart cards into computer security systems should follow certain principles in order to be useful and gain acceptance.

\section{EMV SPECIFICATIONS}

In 1993, EMV standards were started and created by a working group - Europay, MasterCard, and Visa with an objective to define a common set of standards for smart cards based payments applications. These standards allow the card and the acceptance device to work seamlessly and securely together. The group was aimed to create a base for interoperability between chip cards and terminals with specifications provide a reliable global framework for the growth of smart card payment applications. EMV-based smart cards offer a solid foundation for a broad selection of payment and non-payment applications such as stored value, e-purse, and loyalty. Over time, these value-added 
applications promise to deliver greater financial benefits than the savings available from the reduction in fraud.VeriFone Inc. (2003) stated that "The EMV specifications focus on the interactions between smart cards and payment terminals. They are designed to apply to a variety of terminals and devices, such as bank automated teller machines (ATMs), point of sale (POS) terminals, electronic cash registers, and PCs.In 1999, the three card associations founded EMV Co. as an independent organization that will continue to manage and enhance the EMV specifications as technology advances and the implementation of chip card programs becomes more prevalent"

Groupe Ingenico (2001) stated the main goals of EMV specifications as follows:

- The card and acceptance device must communicate together, and indicate what the applications, the card and the acceptance device have in common.

- $\quad$ The acceptance device can run common applications and ensure minimum standard for risk control, and security are applied for debit and credit applications.

- $\quad$ The micro-processor-based payment card provides worldwide acceptance and interoperability.

\section{DRIVERS FOR CHANGE}

EMV has been introduced for several reasons, including:

- $\quad$ Reduction of fraud.

- $\quad$ Additional applications added to the chip embedded.

- $\quad$ Reduction of online traffic whilst maintaining security.

- $\quad$ Allowing issuers to change and control data post-issuance.

EMV smart card guarantees that the stored data is securely held on a chip and not on an easily accessible and changeable magnetic stripe, where copying of cards will become very difficult. It can also provide more secure offline processing of transactions, which reduces the incidence of offline fraud that can occur when cards are not validated against the issuer's card and account records.

Moreover, the chips equipped with EMV applications provide significantly more memory capacity than the relatively few bytes available on a magnetic stripe card. EMV allows transactions to be performed offline while still providing a mechanism to authenticate the card and verify the personal identification number (PIN), and this reduces the cost of online transaction.

Another mechanism provided by EMV is that issuer can update data on the card after the card has been issued, and he will be able to block or disable the card application or even the whole chip itself when necessary.

\section{BENEFITS OF SMART CARDS}

The general benefits of smart cards are unlimited, but the most important ones are convenience, speed, easeof-use, flexibility, accuracy, cost saving, authentication and security.

In technology environment, computers, communication networks and Internet play a vital role in our daily lives. Therefore, the evolution of smart card that began twenty years ago is considered as a major value-added to the world of technology. Like the computers, smart cards are very beneficial to the consumer for carrying his daily transactions more conveniently.

The transactions can be carried out either online or offline through any suitable hardware or payment terminal anywhere, anytime seven days/24 hours.

Smart cards solve many problems and serve in many different fields, ranging from building access control to electronic payments. The technical advances offered by the smart cards and the emergence of other technologies such 
as Internet, mobile phones and public key infrastructure (PKI) enable the consumer to make totally new payment methods with a very high level of privacy and security.

Smart cards ensure data protection as information is exchanged between the card and the card reader. Data stored on the card are encrypted, safeguarded and cannot be forged or probe. The cardholder is urged to enter his PIN for verification so any unauthorized access will be prevented.

Smart cards become important and useful tools in the PC environment. They also provide vital components of security system for data exchange throughout virtually any type of network. Smart cards strongly protect data against security threats such as careless storage of user passwords, card thief attempts to guess the PIN to access the keys, and any other system hacks.

Nowadays, consumers feel they carry several cards such as debit/credit cards, driver license, health cards, club membership cards, etc. in his pocket, which are all fighting for a place "share of wallet" (OTI America, 2004).

Therefore, the main objective of smart card to be smart is the ability to carry the multiple applications all in one card.

\section{CURRENT SMART CARD APPLICATIONS}

With the rapid expansion of Internet technology and electronic commerce, smart cards are now widely accepted in a number of applications as stored-value cards (SVCs) and secure storage cards. Many card applications serve similar purposes or make use of similar resources to perform the services provided.

These applications are suitable and feasible to integrate together in order to increase functionality of the card, and decrease the resources spending by sharing common required information. Chan (1997) stated that one of the conditions for applications to be united is that they have to be governed by a single specification or standard under a certain authority. This section focuses briefly on a few of many applications, which are currently being used by the smart cards. The applications of smart card can be classified as follows: Electronic Payment, Security and Authentication, Transportation, Telecommunication, Health Care and Loyalty program Applications.

\section{ELECTRONIC PAYMENT APPLICATIONS: LECTRONIC PURSE}

HKUST Cyberspace Center (1998), Mantyla (2001), and Netcaucus Organization (2001) identified e-purse or electronic cash as a virtual effort to replace cash with smart card based payment system. The basic idea is that the consumer no longer requires carrying any cash with him, and funds can be loaded electronically onto a memory or microprocessor smart card. Several small purchase transactions can be carried by smart card such as car parking, meals, magazines, copies from copy machines, etc. The widespread adoption of e-purse can reduce the cost to banks and retailers in handling large quantities of cash.

Since 1994, the e-purse development has been extended in Europe and then widely adopted all over the world. Several global card projects have been developed for this purpose, such as "VisaCash" by Visa International.

Also, in the Kingdom of Bahrain, a new project is going to be implemented very soon and called "e-purse" project. Al-Khalifa (2004) demonstrated that, by using the smart card, the cardholder may deposit cash amount on his microchip card to pay his government transactions fees without the need to carry coins, credit cards or even ATM cards.

\section{STORED VALUE CARDS}

Stored-value cards (SVCs) are also known as electronic tokens, electronic tickets or electronic purses. These electronic tokens can be stored in the smart card memory for different services, and can also be refilled depending on 
the types of the memory card. The card can be used to fill the car tank at petrol station and for the parking meters, pay $\mathrm{TV}$, cinema, vending machines and convenient stores.

The advantages of this system are avoiding coins collections, reducing operation overhead and eliminating theft. The consumer also no longer needs to carry heavy coins around. This stored-value cards system is a better shopping model to be derived, where card can monitors the patterns of use, merchants and consumers can easily retrieve the information stored in the card as well.

\section{SECURITY AND AUTHENTICATION APPLICATIONS: CRYPTOGRAPHIC USES}

Petri (2003), Netcaucus Organization (2001) and HKUST Cyberspace Center (1998) demonstrated that current sate-of-the art smart cards have sufficient cryptographic capabilities to support popular security applications and protocols. In general, the major requirement of using smart card system is to ensure that the card presented is valid, used by the entitled person, and to protect data as information exchanged between the card and the card reader. Thus, smart card has the ability to configure multiple personal identification numbers (PINs) and can provide high level of security for different purposes such as confidentiality, user authentication, application authentication and transaction authentication, and non-repudiation.

Most of the abovementioned security needs can be met by using public key infrastructure (PKI), which makes smart card more trust worthy. PKI provides the policies and procedures required for data transmission. PKI includes data encryption to ensure confidentiality, digital certificates to provide authentication, and digital signatures making sure the transaction was completed by the originator, without intervention or error. The technical details are beyond the scope of this project. For more information, please visit http://www.netcaucus.org/books/egov2001/ pdf/SmartCar.pdf

\section{IDENTITY CARD}

Identification of an individual is a very complex process in the field of information technology. In the process of identification, the cardholder has to identify himself, and the system should recognize the legal user who generates the incoming connection. So the responsibility for user authorization lies on the system where the smart card plays an important role here.

Smart card is not only used to store information about the user, but also used to identify that the holder is the correct owner, and the information stored can be verified locally against the password or PIN before connection is made to the host.

There will be some personal information about the owner physically printed on the surface of the card such as cardholder name, ID number, sex, date of birth, etc. (HKUST Cyberspace Center, 1998 and Chan, 1997).

According to Al-Ayam Daily Local News 2004. "Bahraini-Malaysian Company Adopted The SmartCard". Al-Ayam Daily Newspaper, vol. $5677\left(20^{\text {th }}\right.$ September 2004) pp. 1 \& 4 the cost of the "Smart Card" project in Bahrain will be BD 3.5 million. This smart card will replace the existing CPR card, the driving license and can also be used to pass through the e-Gates, which simplifies the process of identification.

\section{ACCESS CONTROL CARD}

Keys, badges and magnetic stripe cards are the most common devices used for physical control access such as office premises, university campuses, and private areas. However, these devices can easily be duplicated, or simply be used by any other illegal user. Therefore, using multifunction, microprocessor based smart cards can overcome these weaknesses because they are very difficult to re-produced and capable of storing digitized personal characteristics. Smart cards can be personalized to allow access to restricted facilities, depending on the cardholder's security clearance. 
Shadfar (2004) and HKUST Cyberspace Center (1998) illustrated that it would be possible to track the staff movement around the building. Staff should have access from anywhere to anywhere, without any security threats, and that could only be achieved through an efficient Identity Management system, which provides secure authentication and the right level of authorization.

\section{COMPUTER LOGIN}

Computers and networks are the backbone of our digital lives in this increasing digital oriented world, and many fundamental security challenges are arising.

There is a security risk while passing information over the Internet because an anticipated party can intercept the information. So, using smart card to log onto the Internet can protect the confidentiality of data transmission. However, logon can be either by a simple serial number, or a more complex operation, which requires entering a PIN or a network password. The access to the computer can be controlled by the smart card where the security of authentication, authorization, privacy, integrity and non-repudiation are increased. In this case, the signing PIN is verified by the microprocessor of the card, which is then compared against the private key stored in the RAM, and if the comparison is negative, the CPU will refuse to work.

In a corporate enterprise, smart cards can also be used as critical electronically tools to improve security for multiple disjointed systems such as e-mail, Intranet access, dial-up network access, encrypted files, digitally signed web as well as building access.

Shadfar (2004), Petri (2003) and HKUST Cyberspace Center (1998) indicated that the information is extremely difficult to decode without PIN keys, and they never leave the card, which prevents them from being intercepted by a third party. For many security advantages offered by smart cards, you can visit http://www.sspsolutions.com/solutions/whitepapers/introduction_to_smartcards/?page=printerfriendly

\section{TRANSPORTATION USES}

Many transportation transactions are being carried nowadays by using smart card technology and especially contacless card. Smart card can act as electronic money, which allows car drivers to pay a fee while they are passing through road barriers or tunnels (Parnell, 2000).

An example is the "Octopus Card" in Hong Kong. With this card, the user can posse a reload-able card that can be debited immediately or as a credit card based-payment system, where monthly settlement would be required.

Al-Khalifa, A. A., 2004. "Electronic Gate in Bahrain Airport Next Year". Al-Ayam Daily News, vol. 5626 ( $31^{\text {st }}$ July 2004) pp. 3 disclosed that "National Smart Card" project will be launched as an electronic gate in Bahrain International Airport in the second quarter of year 2005.

\section{TELECOMMUNICATION APPLICATIONS}

Telecommunication is one of the largest markets for smart card applications. Since 1988, smart card has become an essential component in cellular phone systems. That various benefits can be gained from using smart card for calls payment, where the consumer needs not to carry coins, and the telephone company will no longer suffer from cash theft.

Parnell (2000) and HKUST Cyberspace Center (1998) provided that network data, subscriber's information and all related critical data are kept inside the card. So, subscribers could make calls from any portable telephone through different destinations, and any calls made through the mobile phone could be encrypted and thus ensure privacy. 
In addition, using smart card could support more and more value-added services, such as electronic banking. Financial organizations and banks can facilitate the process of loading funds from the bank account onto the smart card wherever a phone is available. These telephone transactions will easy the funds transfer process from person to retailer, bank to account holder and even person to person.

\section{HEALTHCARE APPLICATIONS}

Smart cards offer a new perspective for healthcare applications due to their multiple security advantages provided for data storage. A smart card with medical applications can be used to store critical information including personal data, insurance policy, emergency medical information, hospital admission data and recent medical records.

HKUST Cyberspace Center (1998) mentioned that numerous national hospitals in France, Germany and Hong Kong have already started to implement this kind of healthcare card.

Like the workflow control system, smart cards can be used for managing the levels of information authorized for different users. Doctors, chemists and administration officer will be able to access the medical record from the patient's card as per their requirements.

\section{LOYALTY APPLICATIONS}

Another important application of smart cards that can be used in shopping model is a Loyalty program. This program can support retailers to strengthen customer relationships and promote specific products or services.

With loyalty application, the smart card is capable to store and process the preferred customer status together with detailed information of his/her shopping habits. The availability of such information would able the merchant to create better shopping model, or tailor personalized customer shopping profiles. The shopping habit profile is stored in the customer's card, where his/her shopping records could remain more confidentially and protected from any unauthorized access

Another smart card utility is "Prepay Utility Meter Cards". This type of card ensures that utilities such as water, electricity and gas are paid for in advance or "pay as you go". This type of utility payment has proved very popular in South Africa (Parnell, 2000).

\section{RESEARCH METHODOLOGY AND SOURCES OF DATA}

This research is designed to examine the importance of smart card adaptation around the world in general, and EMV migration in the Kingdom of Bahrain in particular, and to study its major impact on customer banking behavior in the short-term, and to investigate the problems facing the banks and/or organizations who are directly involved in EMV program. To describe the research design, this chapter has been organized into the following sections: (1) Research framework and constructs, (2) Sample selection, (3) Research instrument, and (4) Data collection and gathering. 
Figure: 1 The Research Design

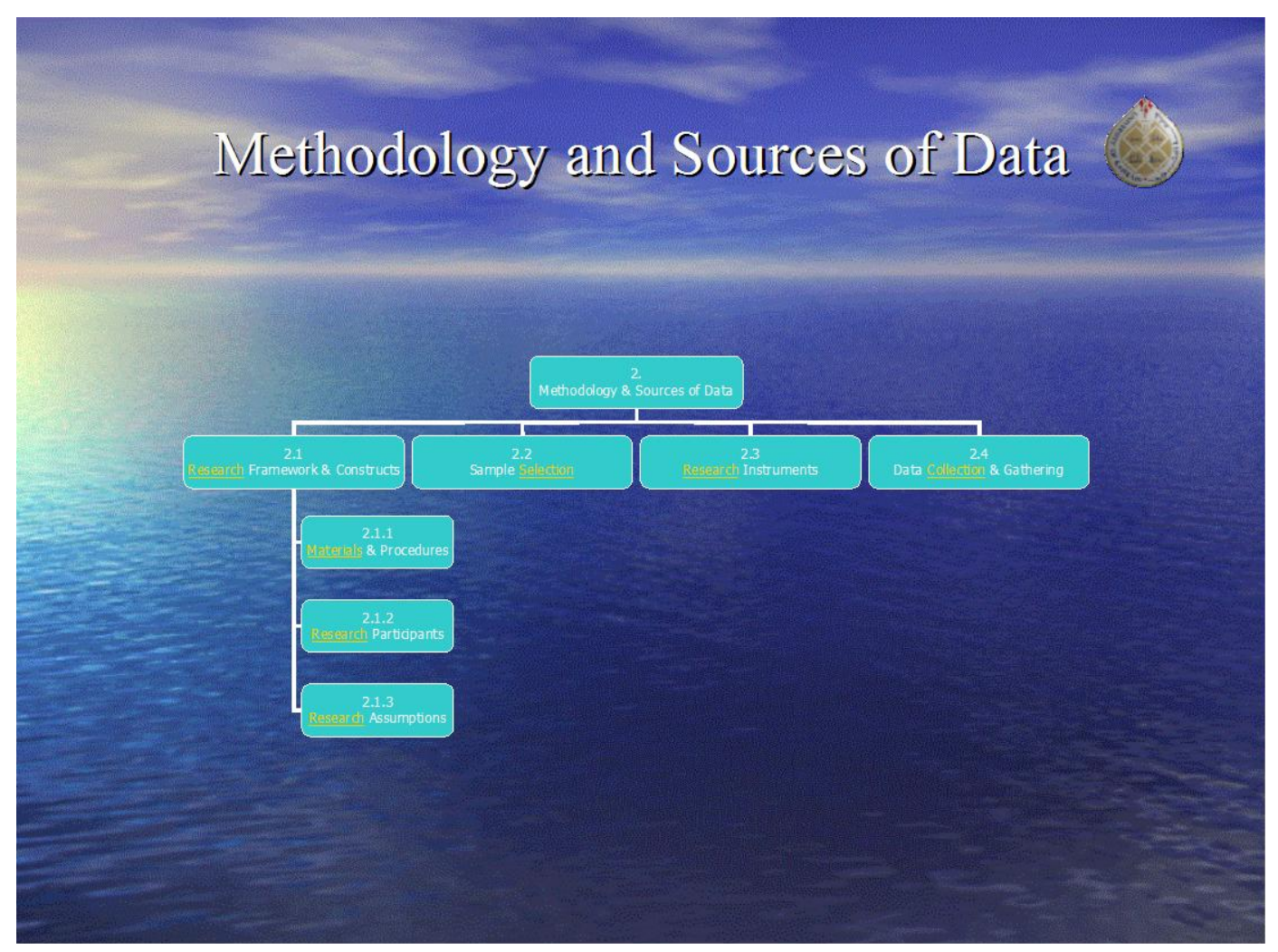

\section{RESEARCH FRAMEWORK AND CONSTRUCTS}

The main objectives of this research intend to examine the major factors related to the EMV smart card adaptation in the Kingdom of Bahrain, and to reveal how prepared Bahrain financial organizations, banks and retailers are in their approach to EMV migration, and to evaluate the important benefits derived from using multi-applications smart card. The following issues represent the framework of this research:

1. The emergence of smart card technology with EMV specifications.

2. The main applications provided to customer.

3. The drivers for change towards EMV smart card.

4. The expected use of EMV smart card in the Kingdom of Bahrain.

5. The constraints and obstacles prevent others to move towards EMV program.

6. The main factors: authorization and authentication that prove high security levels.

7. How EMV program in the Kingdom of Bahrain will be developed and improved.

8. How consumer banking, payment and purchasing habits will be affected.

9. How Bahrain banking sector views the future of EMV migration. 


\section{MATERIALS AND PROCEDURES}

The Qualitative research methodology was chosen to approach the problem because of the following:

- $\quad$ The need to solve research questions generated in the beginning through deductive logic.

- The need to validate relationships between certain measurable variables. (E.g. the relationship between the smart card based-payments and security).

- $\quad$ The need to examine the problems facing the Bahrain financial organizations, banks and retailers.

- To illustrate a holistic view of EMV smart card adaptation in the Kingdom of Bahrain.

Among the qualitative research tools, the interview was found the most appropriate for the following reasons:

- The best access to interpretations of the participants has about actions and events taking place and views on the aspirations of themselves and other participants.

- $\quad$ The ease of conducting the interviews within specific period.

\section{RESEARCH PARTICIPANTS}

For the purpose of studying the prospective of only Bahrain local banking sector in smart card and EMV adaptation, the interview participants were five local banks/financial organizations who are highly concerned in the program. Those are Bank of Bahrain and Kuwait - (CrediMax), Bahrain Shamil Bank, National Bank of Bahrain (NBB), Central Informatics Organization (CIO), and Arab Financial Services Company (AFS). Participants were asked to provide the following personal information: Name, Job Title, Company, and Industry sector.

\section{RESEARCH ASSUMPTIONS}

- The interview sample is a good representation of Bahrain financial banking sector.

- $\quad$ The interview questions were clear and precise.

\section{SAMPLE SELECTION}

The targeted sample of interviews was selected through the literature review stage, while some were chosen randomly based on the expectations of the study, and their contact numbers were drawn from 24hrs directory line of Bahrain Telecommunication Company (Batelco). Out of each, only one person was selected except AFS two persons were chosen. From the interviews conducted, it was noticed that the participants were in the management level and from IT department or Card Center, and were directly involved in EMV project.

\section{RESEARCH INSTRUMENT}

The instrument used to collect data on the EMV migration in Bahrain banks/organizations was an interview. The interview was mainly used for acquiring the primary data, includes twenty-seven questions and can be classified into the following key elements:

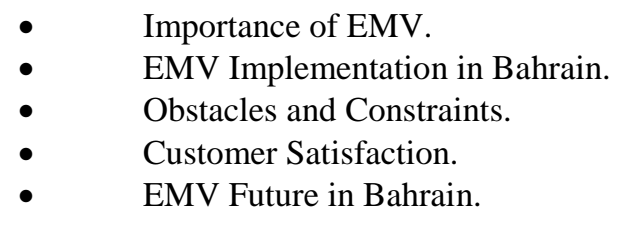

The questions are about the major differences between EMV smart cards and current traditional magnetic stripe card, important benefits gained from EMV smart card, multiple applications offered by EMV smart card to customer, the impact of EMV implementation on Bahrain banking sector policy, strategy for change, and preparation 
methods to face such a new emergence of technology, stages of implementation, the deadline for EMV migration, problems and/or obstacles encounter due to the migration processes, training programs in place for staff members, evaluations of customer behavior and his feedback, whether EMV project considered as an investment opportunity, to what extent EMV enhance the security level, and finally, the expectations about EMV future in Bahrain. Based on the interviews conducted, it was found that four interviewees were cooperative, helpful with immediate response, however the other two were unfortunately not supported very well.

\section{DATA COLLECTION AND GATHERING}

The major source of data to be collected were the interviews handheld, while the previous studies conducted on smart card evolution and EMV implementation which are included in the literature review (Academic journal, research papers, articles and books) were the secondary data of the research. Unfortunately, some of the banks/organizations interviewed were not responding with us due to some reasons.

Figure: 2 Data Collection and Gathering

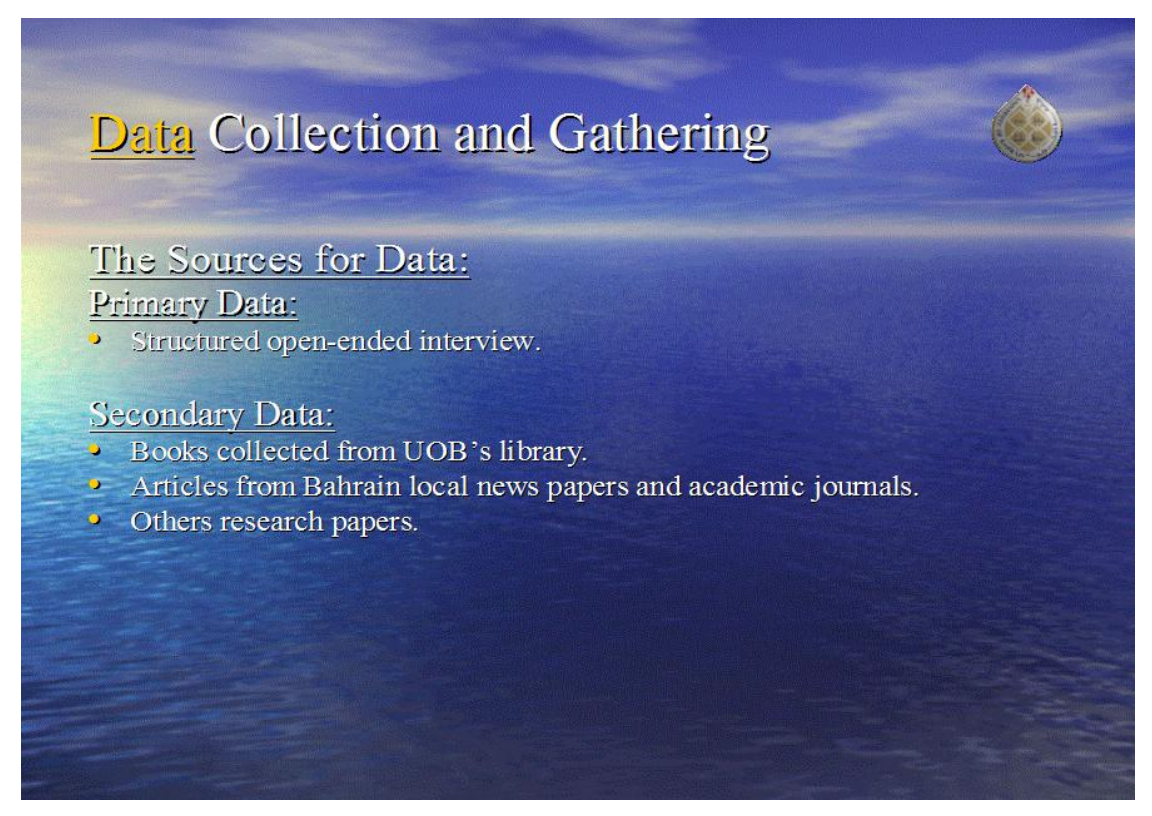

\section{FINDINGS: DISCUSSIONS, ARGUMENTS AND ANALYSIS}

This chapter summarizes all the responses obtained from the four interviewees in order to view their organizations experience with multifunction smart card and EMV standards. The findings will be reviewed and analyzed according to the understanding, and compared with the related literature issues as it is mentioned earlier in the literature review section. Whereas, in the next coming chapter a conclusions related to the smart card usage and EMV migration in Bahrain will be provided.

The research questions can be classified into the following key elements: Importance of EMV, EMV Implementation in Bahrain, Obstacles and Constraints, Customer Satisfaction, and EMV Future in Bahrain. 


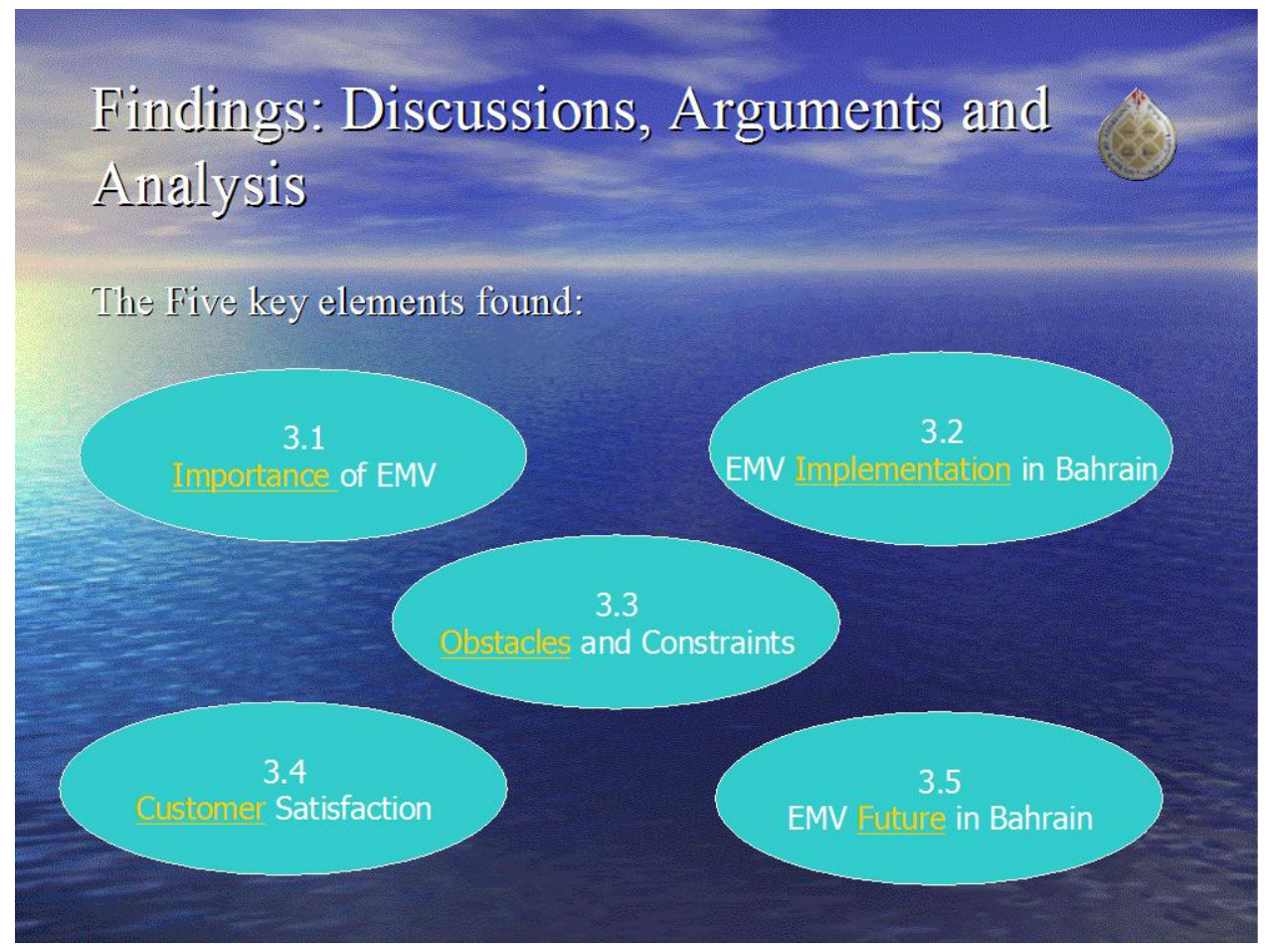

\section{IMPORTANCE OF EMV}

With regard to the major differences between EMV smart card and the current traditional magnetic stripe card, it was found that all interview participants have agreed on that EMV smart card with an embedded chip is more advanced in specification technology and different format for multifunction purposes. EMV smart card can combine payment with other value added applications such as identity, healthcare, communications, loyalty, etc. on a single card. Mr. Nader Al-Soufi the Head of Business Development, CrediMax said "Smart card with EMV standard is more secured to the cardholder", and Mr. Mahmood Al-Ansari the Quality \& Compliance Manager, AFS said "This card can avoid any fraud transactions due to cryptographic enhancements". Regarding the traditional magnetic stripe card Mr. Al-Ansari said "Such card can only provide a single function such as payment with access to savings or checking account (debit card), or payment access to line of credit (credit card)".

However, with respect to the important benefits that can be gained from EMV smart card over the current magnetic card, it was found that EMV card can be a multi-application card with various features such as personal identification, fraud reduction, ability of offline transactions, scripting, high level of security because of the use of PIN number for online authorization, and the confidentiality of data which can be kept safely on the embedded chip due to authentication and validation. Also, loyalty program and point system campaigns are additional features provided by this card. By using EMV card there is an ability to manage a growing number of transactions, and ensure interoperability of different debit/credit applications. For example the user can get involved into other areas of shopping worldwide more conveniently. Mr. Yousif Al-Khan the Senior Manager IT, Shamil Bank highlighted the reason of "Why EMV?" and said, "Because the big consumers in the world are MasterCard customers that most of them will be highly encouraged for EMV card". He also provided that "There will be a less requirement for insurance, and because of authentication feature on the smart card itself there will be a reduction in traffic either online and/or offline and that will definitely fast the process of any transaction, while magnetic stripe card is unable for authentication". 
On the other hand, Mr. Al-Khan said "Shamil Bank smart card will be used as a single application card for e-purse purposes only, and this will enable the customer to transfer cash from his bank account to his smart card, which will then replace the cash put in the pocket and ATM cards as well.

\section{EMV Implementation in Bahrain}

A general question was addressed to the interviewees about the major sectors in Bahrain who are nowadays toward EMV implementation, and they provided that most ministries in Bahrain such as Ministry of Health, and health care centers, Banks (Issuers and Acquirers) - Issuers are all banks with Visa/MasterCard, and Acquirers such as CrediMax and National Bank of Bahrain (NBB) - and other financial organizations such as AFS and airlines companies are on their way to EMV migration.

Regarding the main reasons behind the migration and how far does implementation of EMV will affect Bahrain banking sector policy, all participants agreed on becoming an EMV compliant, and that is because of customer requirements, security and being mandated by Visa and MasterCard International. Mr. Al-Ansari said, "None beyond the MasterCard and Visa mandates", and Mr. Mohammed Nass the Assistant General Manager Operations, AFS said, "It is important and if AFS does not do they will lose their business". Whereas, Mr. Al-khan said "Bahrain Shamil Bank has the interest but it is just at the initial or research stage".

This issue will greatly affect the business of the issuers/acquirers each in a different manner. Mr. Al-Soufi confirmed that "For acquires such as CrediMax, this will make the transactions more secured, and the customer will be able to utilize his card in a much better and secured way in a much faster speed". While Mr. Nass said "It will affect on two ways, inbound and outbound. By inbound, we mean (Acquirers) if they are not ready they will be unable to cash or cannot do transactions, and the financial reputation of Bahrain will also be suffered. On the other hand, the outbound (Issuers) may lose money, business and customer satisfaction". Mr. Al-Khan also said "Bahrain is very advanced in technology and this is a real key factor that will make Bahrain capable for e-government. Many organizations in the Kingdom are nowadays toward EMV implementation such as BBK, Credit card, CIO, Traffic Directorate and Ministry of Health".

From the responses gathered, it was found that all the interviewees were directly involved in EMV program with different aspects, tasks and objectives. For example Mr. Mohammed Nass the Assistant GM Operations, AFS his objective was to be an EMV compliant before competitors. While Mr. Mahmood Al-Ansari the Quality \& Compliance Manger, AFS his task was to produce multiple flavors of smart cards depend on client requirements. However, Mr. Nader Al-Soufi the Head of Business Development, CrediMax is mainly involved in promoting and advertising the product. And Mr. Yousif Al-Khan the Senior Manager IT, Shamil Bank has been involved in some tasks of the project asked by top management. He said, "We are looking for introducing new products/services and in future will apply MasterCard standard".

The participants also clarified that their banks/organizations strongly accepted the idea and they are pushing for it to a great extend to be among the leader, and for competition and differentiation. Mr. Nass said, "AFS has no choice, no options and they must accept". And based on the questions addressed to them about the strategy of their banks/organizations, and the preparation methods to face the emergence of this new technology, their answers are summarized as follows:

- $\quad$ The strategy of CrediMax (Card acquirer) is to replace all the existing cards, educate customers and let them feel the difference. CrediMax preparation methods are changing the existing system totally, updating all the ATM machines and upgrading all their point of sales (POS) machines. Therefore, their major steps in EMV project are changing the system and upgrading the ATMs and POS machines, ordering cards, agree on the functionality of the cards, replacing the existing cards, and create awareness and educate the cardholders. CrediMax has chosen an HPS company as an external consultant for this project. "CrediMax has reached upgrading system stage in the implementation process and not yet formulated any test plan. It will be in year 2005" said Mr. Al-Soufi.

- Meanwhile, Shamil Bank's future strategy is to move from the existing magnetic stripe card to EMV standards. Currently Shamil Bank has assigned personnel from different departments such as IT, marketing 
and credit card center. They only employed people with different skills and knowledge in smart card technology. "Shamil Bank now is in the initial stage and has just started with research in technology and marketing issues, and if accepted Shamil will definitely upgrade all ATMs, and will checkout if there is room for EMV smart card upgrading. And at each single stage of a project we do testing, we have prototyping plan and parallel test run. There are two major steps for implementation technically wise and marketing, it needs to verify whether the bank is technically capable for such a project and study the market for competition" said Mr. Al-Khan. He also said, "Shamil Bank current credit card is publicly used in GCC".

- However, a full project team was established by AFS company (Issuer) with a major strategy included gaining knowledge prior to the migration plan, acquiring hardware and software, and hiring new people such as training consultants (SIMETRIC) nominated by Visa International Organization. So, their major steps of strategy development were changing software applications, personalization, purchasing hardware and training. AFS also chose different suppliers such as IBM for main machines, NBS for embossing and personalization, and BAYSYS for software applications and upgrading. "AFS is now ready and has become an EMV compliant in the third quarter of 2004." Said Mr. Ghazi M. AbdulJawad, the Chairman, AFS and Mr. Nass.

Figure: 4 Major Sectors in the Kingdom of Bahrain towards EMV Migration

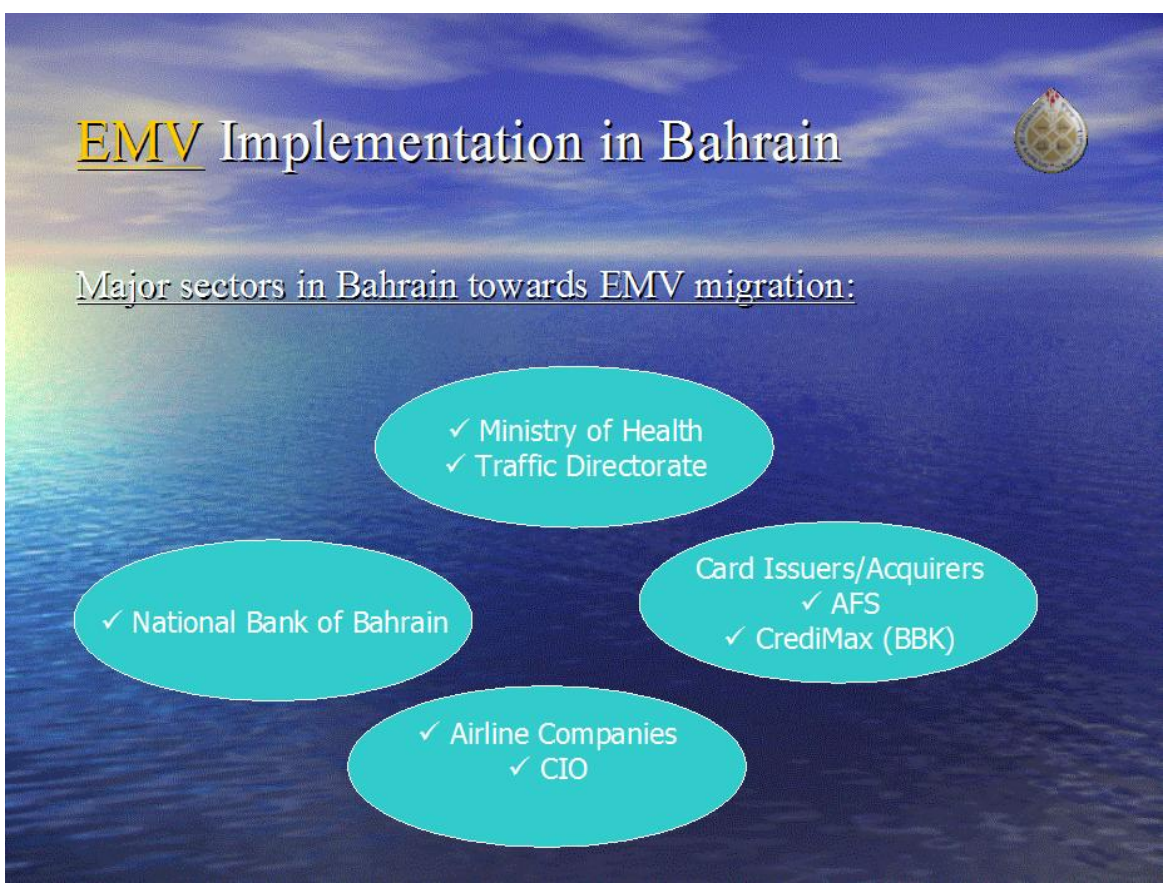

Moreover, all the interviewees agreed on that there will be a pilot testing while running both systems together - card with magnetic tape along with chip card - and gradually the magnetic card will be withdrawn from the market at a later stage based on its expiry date. Mr. Nass said, "Because of shifting liability, it has to replace the magnetic card but off course gradually move till the current card be reduced and this depend on the mandates or time schedule". It was also found that although some banks/organizations in the kingdom are ready for rollout in year 2005 such as AFS, others are not or at least not in fully operations such as NBB. Generally Bahrain would expected to be ready for rollout and the mandate is year 2006. 
Figure: 5 The Strategy and Implementation Methods - CrediMax and Bahrain Shamil Bank

\section{EIVIV Implementation in Bahrain (cont'd)} Strategy and Implementation Methods:

CrecliMax:

7 Changing the existing system totally.

$\checkmark$ Upgrading the ATMs and POS machines

$\checkmark$ Ordering cards, and agree on the functionality of the cards.

I Replacing the existing cards.

( Create awareness and educate the cardholders.

$\checkmark$ CrediMax has chosen an HPS company as an external consultant for this project.

$\checkmark$ CrediMax has reached upgrading system stage.
Shamil Bank:

$\checkmark$ To move from the existing magnetic stripe card to EMV standards.

$\checkmark$ Shamil Bank has currently assigned personnel from different departments with different skills and knowledge in smart card technology.

$\checkmark$ Shamil Bank is now in the initial stage and has just started with research in technology and marketing issues.

Figure: 6 The Strategy and Implementation

Methods - Arab Financial Services (AFS)

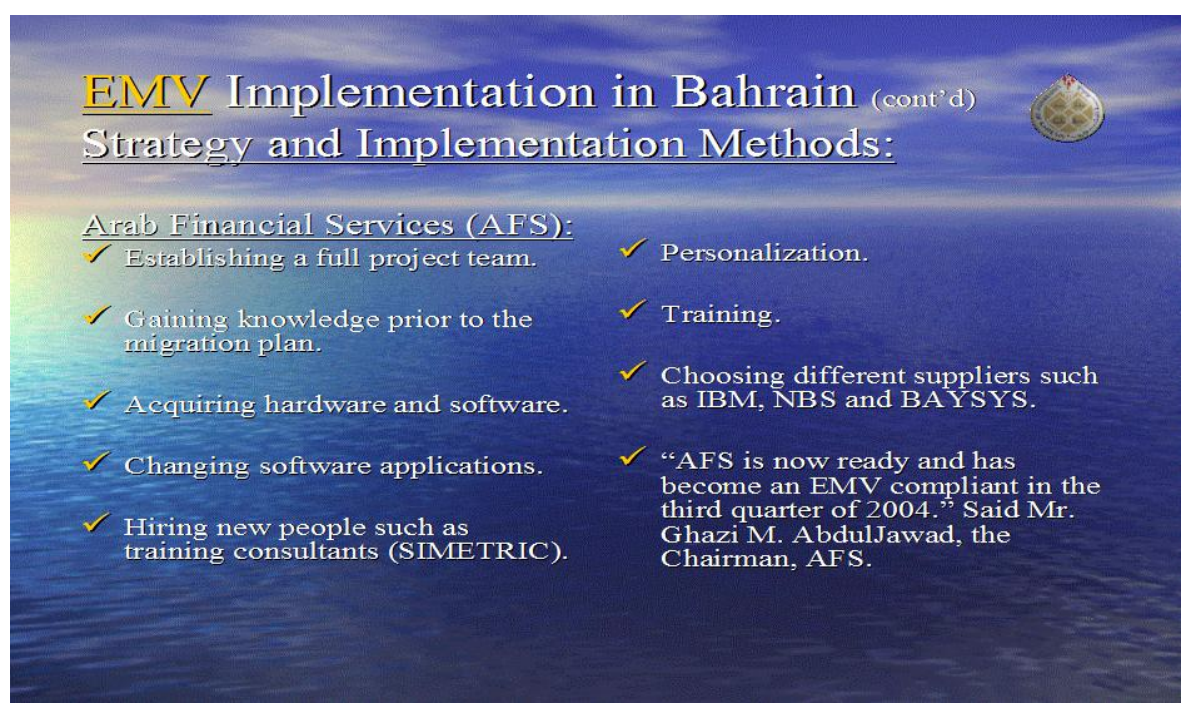

\section{OBSTACLES AND CONSTRAINTS}

With respect to the main problems and obstacles that may face those banks/organizations during EMV implementation project, Mr. Al-Soufi said "No obstacles yet". While Mr. Nass said, "Only teething problems, i.e. Decisions and knowledge at the beginning stage". However, Mr. Al-khan said, "In our case, as we are moving toward 
MasterCard standard such obstacles are not applicable, and also our budget for this project is sufficient". So based on his answers provided it seems that meanwhile Shamil Bank is far behind EMV migration project.

On the other hand, and with regard to the impact of refusing to adopt EMV standards, MR. Al-khan said "Penalty, only if compulsory, and for that reason Shamil Bank will pay penalty costs". And this agreed by Mr. AlSoufi who said, "If refused, CrediMax will pay penalties and will be liable for any fraudulent transactions". While this is not applicable for AFS as an issuer, but they off course will lose business.

Also, regarding education and/or training programmes in place for the staff, CrediMax will decide on by the end of this year 2004. While, Shamil Bank has not decided and no organized training programmes offered yet, as they are only at R\&D stage. Mr. Al-Ansari added, "Awareness coerces by the consultant".

It was also found that for acquirers such as CrediMax, NBB and Shamil Bank, EMV implementation project is considered as an investment opportunity in the short-run, since it will reduce transactions to a great extend and will minimize their loss. Mr. Al-Khan said, "Off course there will be a Return On Investment (ROI), direct and indirect. Direct Return such as reduce amount of frauds and reduce in customers' complains, and Indirect Return such as more customer attraction which leads to more business". On the other hand, for AFS this project is not an investment. MR. Nass said, "It is just like to do or not, if not do it AFS will definitely lose their business and we have spent on the project about $\$ 2.5$ million, and I expect that acquirers may need approximately \$5 million for such a project”. But Mr. Nader did not mention the estimated budget assigned for EMV project.

The participants finally explored that the budget and cost of the project are the main constraints that may prevent others to move towards EMV migration. The complexity and to what extend their existing system is ready to convert is also another constraint. Mr. Al-Khan said, "It depends on how it is compulsory and must. The obstacles that might face them are the hardware infrastructure, some banks have a very old system machines, and this depends on how the management is looking at this issue".

\section{CUSTOMER SATISFACTION}

Here, the interview participants were asked about how are they going to launch/promote for EMV smart card publicly, how can they evaluate customer feedback, and whether he/she be asked for additional fees. The responses gathered indicated that there would be a thorough education campaign, and create awareness to everybody, and this depends on the market situation. And in case of evaluating customer feedback, "It can be evaluated based on the market situation as well, and the customer will not be charged any fee" said Mr. Al-Soufi and Mr. Al-Khan, but "some banks may ask" said Mr. Nass.

Furthermore, another question was addressed to the participant about the bank future plans towards customer acceptance and/or reluctance to change. Mr. Nader said, "I do not think there will be any resentment from customer's side, because the process will be through replacing his card with no fees charged to him, and with the same functionality", and his answer was agreed by Mr. Al-Khan.

Finally, regarding security issues which is considered as a major requirement of customer satisfaction, interviewees provided that actually there will not be a $100 \%$ guarantee of security, and there is not an absolute solution, but EMV will definitely guarantee security to a satisfied limit for its high improvement in technology.

\section{EMV FUTURE IN BAHRAIN}

Eventually all other banks, merchants and retailers in the kingdom of Bahrain shall proceed to EMV migration with no choice because of the mandates. Mr. Yousif al-Khan said, "I agree on smart card, and I believe that if Bahrain move towards smart card, this will put her among the leader and there will be more competition in the region. Bahrain citizens are always looking for advance technology, have a very rich knowledge about information technology, well literate and are capable for using such a smart technology". 


\section{CONCLUSIONS}

The principal conclusions drawn from the interviews carried were that there is sufficient awareness in Bahrain about the necessity of smart card usage and EMV standards. A smart card basically means a unique, small portable, personal object with an intelligent embedded microprocessor chip providing memory storage, processing power, and can easily combine secure identification and authentication functions for both physical and digital world. Where EMV is an agreed specification between Europay, MasterCard and Visa Internationals for the interoperability of smart cards and terminals equipped with smart cards readers for debit and credit payment schemes, ensuring global operations through terminals compliance with EMV standards (Mosiac Software UK Ltd, 2001).

The importance of smart card with EMV standards will rapidly increase over the coming years as users obtain powerful worldwide operations with multi-applications, and businesses use information more and more for data storage, and decision-making as a strategic weapon. It is said, "Smart card will become in the near future as important as computers are today" (Petri, S. 2003).

It can also be concluded that there is an acceptance by some ministries, banks and financial organizations in the Kingdom of Bahrain of becoming EMV compliant, and they are now in their way toward EMV migration. Those are Ministry of Health, CIO, BBK, NBB, CrediMax, Shamil Bank and AFS. Shamil Bank has just started the R\&D stage, while CrediMax has reached upgrading system stage, whereas AFS has already adopted the complete system and become EMV compliant in the third quarter of this year 2004.

The main reasons behind the EMV migration are customer requirements, privacy, security and being mandated by Visa and MasterCard Internationals. This issue will greatly affect the business of the issuers/acquirers each in a different manner. For example, for acquirers the transactions can be carried more securely and the customer can utilize his card more conveniently around the world in a much faster speed. So acquirer must adopt EMV specification, otherwise they may not be able to cash or run transactions, and will definitely affect the financial reputation of Bahrain. However, the issuer if not do it may lose money, business and customer satisfaction.

To implement EMV, both issuer and acquirer need to have a sufficient budget, knowledge, a qualified workgroup and good preparation methods to face such a new emergence. Education and training programs provided to the staff members, and an intensive promotion campaign and clear awareness were also required to avoid any reluctant to change.

The use of smart card with EMV specifications is growing rapidly in many different regions around the globe because of many benefits and features obtained. In the few coming years, cardholders will carry an empowered device with multiple applications and high level of security, while business organizations will achieve easy and rapid data access and system interactions.

In summary, a smart card with an ICC has become the driving force for many business organizations around the world to adopt this new technology in many distinct application areas like e-purse, e-commerce, mobile phones, healthcare, network security, etc. Organizations can make the time critical for decision-making, updating or writing data to the card post issuance that is required to remain competitive and differential.

\section{RECOMMENDATIONS}

Many issues may arise due or even post implementation progress, which need to have a clear understanding and prior preparation. Therefore, in order to avoid the unsatisfactory situations and reach to a successful system and well-satisfied customers, Issuers/Acquirers, and other interested organizations are recommended with the followings:

- They are advised to restrict to the rollout time schedule to avoid liability, loss of money, loss of business, loss of customer's satisfaction and Bahrain's financial reputation.

- They are advised to study the project thoroughly and set a sufficient budget as it is considered one of the most obstacles prevent others to move towards EMV migration. 
- $\quad$ They are advised to assign a full project team consists of IT experts, smart card specialists and members from other functional areas such as marketing, finance and management.

- $\quad$ They are advised to gain sufficient knowledge about the foreign banking sectors in comparison with the local market.

- $\quad$ They are advised to study to what extent the local IT infrastructure suites other advanced countries such as Europe, US and other Middle East countries to ensure cross based-payment system.

- $\quad$ They are advised to provide their staff members with education and training programmes to cope with the updated system changes.

- $\quad$ They are also advised to educate their existing and potential customers and provide them with a clear awareness about the expected changes may affect the current system through rich promotion and advertising campaign.

- $\quad$ They are advised to convince their customers with the critical benefits, latest advents provided by the smart card and ensure security.

- $\quad$ The interested parties who have not yet committed with EMV project are highly advised to investigate to what extent it is compulsory and must to avoid penalties.

- $\quad$ Finally, to be or not to be an EMV compliant may be an optional issue for some particular countries as for US who disagrees for various reasons. And this leads us to question, how shall US defend and interpret its point of view in this matter?

\section{REFERENCES}

1. Access Keyboards Ltd. (2003) What is EMV http://www.accesskeyboards.co.uk/emv\%20overview.htm accessed $24^{\text {th }}$ July 2004.

2. Agarwal, A., Arora, R., Badwe, N. and Hain, M. (2003) XML Agent for Smart Cards Bachelor of Engineering Project, University of Mumbai p.8-10 http://www- scf.usc.edu/ badwe/sitefiles/beproject.pdf accessed $1^{\text {st }}$ August 2004.

3. Alajmi, S. (2004) Electronic Gate in Bahrain Airport Next Year, Al-Ayam Daily News, Vol. 5626 (31 ${ }^{\text {St }}$ July 2004) pp. 3

4. Alayam Daily Local News (2004) Bahraini-Malaysian Company Adopted The SmartCard, Al-Ayam Daily News, Vol. 5677 (20 $0^{\text {th }}$ September 2004) pp. 1 \& 4.

5. Al-Khalifa, A. A., (2004). Electronic Gate in Bahrain Airport Next Year. Al-Ayam Daily Newspaper, vol. 5626 ( $31^{\text {st }}$ July 2004) pp. 3

6. Antonides, G., Amesz, H. and Hulscher, I. (1999) Adoption of payment systems in ten countries - a case study of diffusion of innovations European Journal Of Marketing, Vol. 33 No. 11/12 pp.1123 - 1135.

7. Arab Financial Services Company (2003) AFS Annual Report - 2003, Kingdom of Bahrain.

8. Brown, S. (2001) Advancing Standards for Smart Card Growth http://www.globalplatform.org/documents/presentations/smart_card_2001_london.pdf accessed $1^{\text {st }}$ August 2004.

9. Budd, A. (2004) Chip \& PIN Training Guide http://www.atoc.org/rsp/chip_pin/docs/guide.pdf accessed $23^{\text {rd }}$ July 2004.

10. Central Informatics organization (2004) Common Guidelines for Interoperable GCC National ID Schemes, Central Informatics Organization p. 13-34.

11. Chan, S. (1997) An Overview of Smart Card security http://home.hkstar.com/ alanchan/ papers/smartCardSecurity/ accessed $1^{\text {st }}$ August 2004.

12. Chan, S. (1997) Electronic Smart Passport/Visa http://home.hkstar.com/ alanchan/ papers/smartPassport/index.html accessed $1^{\text {st }}$ August 2004.

13. Chan, S. (1997) Infrastructure of Multi-Application Smart Card http://home.hkstar.com/ alanchan/ papers/multiApplicationSmartCard/index.html accessed $1^{\text {st }}$ August 2004.

14. Clark, R. (2003) Is the US ready for smart cards yet? http://www.usingrfid.com/features/read.asp?id=1 accessed $23^{\text {rd }}$ July 2004.

15. Dr. Everett, D. (1995) Smart Card Tutorial: Smart Cards From There to Here - Part 1 http://www.smartcard.co.uk/downloads/freetutorials.pdf accessed $1^{\text {st }}$ August 2004. 
16. Framer, D, and Tonac, R. (2003) What's so smart about Smart Cards? http://www.gemplus.com/smart/ basics/download/smartcardforum.pdf accessed $1^{\text {st }}$ August 2004.

17. Gordeev, M., Hassler, V. and Manninger, M (2001) mart Card Protection Profiles: An Overview http://www.expotrack.com/iccc/proceedings/pdf/proceed/english/track5/p042_e.pdf accessed 23 $3^{\text {rd }}$ July 2004.

18. Groupe Ingenico (2001) An Introduction to EMV: The Smart Card Industry Standard www.ingenico.com accessed $23^{\text {rd }}$ July 2004.

19. Haghiri, Y. and Tarantino, T. (2002) Smart Card Manufacturing: A Practical Guide Great Britain: John Wiley \& Sons, Ltd.

20. HKUST Cyberspace Center, (1998) Guide to Smart Card Technology http://www.cyber.ust.hk/ handbook8/hb8main.html accessed $25^{\text {th }}$ June 2004.

21. Lambrinoudakis, C. (2000) Smart card technology for deploying a secure information management framework Information Management \& Computer Security, Vol. 8 No. 4 pp.173-183.

22. Mantyla, M. (2001) Smart Card Payment and Risk Scenarios http://www.tml.hut.fi/Studies/T110.501/2001/papers/mika.mantyla.pdf accessed $1^{\text {st }}$ August 2004.

23. Millar, B. (2004) BasicCards 101 (Part 1) Program Your First Smartcard, in, Circuit Cellar issue 164, March 2004 http://www.basiccard.com/circuit_cellar.pdf accessed $1^{\text {st }}$ August 2004.

24. Mosaic Software (UK) Ltd. (2001) EMV Smart Card Solutions with Postilion http://www.technologyforfinance.com/PDF/MosaicSoftwareEMVSmartCard.pdf accessed $23^{\text {rd }}$ July 2004.

25. Netcaucus Organization (2001) Smart-Card Devices and Applications http://www.netcaucus.org/books/egov2001/pdf/SmartCar.pdf accessed $1^{\text {st }}$ August 2004.

26. Nyberg, L. (2003) The Swedish Card Payment Market - Current Challenges and Future Developments http://www.riksbank.com/upload/7509/030203e.pdf accessed 23 ${ }^{\text {rd }}$ July 2004.

27. OTI America (2004) The Smart Card Evolution: An introduction to the benefits of contactless, microprocessor-based smart cards and devices www.otiamerica.com and http://www.otiglobal.com/ pdf/The\%20Smart\%20Card\%20Evolution.pdf accessed $1^{\text {st }}$ August 2004.

28. Parnell, K. (2000) Using CoolRunner CPLDs in Smart Card Reader Applications, in, Xilinx issue WP 118 (v1.0) May 2000 http://direct.xilinx.com/bvdocs/whitepapers/wp118.pdf accessed $1^{\text {st }}$ August 2004.

29. Petri, S. (2003) An Introduction to Smart Cards"http://www.sspsolutions.com/solutions/whitepapers/ introduction_to_smartcards/?page=printerfriendly accessed $1^{\text {st }}$ August 2004.

30. Piper, F., Robshaw, M. and Schwiderski, S. (2004) Identities and Authentication http://www.foresight.gov.uk/servlet/Controller/ver=2773/userid=2/Identities\%20and\%20authentication.pdf accessed $23^{\text {rd }}$ July 2004.

31. Plouffe, C., Vandenbosch, M. and Hulland, J. (2000) Why smart cards have failed; looking to consumer and merchant reactions to a new payment technology? International Journal of Bank Marketing, Vol. 18 No.3 pp.112-113.

32. Shadfar, S. (2004) Smart Card-Based Identity and Access Management http://www.sis.slb.com/media/about/whitepaper_smartcard.pdf accessed $1^{\text {st }}$ August 2004.

33. Thales e-Security, Inc. (2004) "EMV - Easy Migration Guide" www.thales-esecurity.com accessed $25^{\text {th }}$ June 2004.

34. UNCTAD secretariat (2001) Chapter-7: Managing Payment and Credit Risk Online, in, United Nations, United Nations Conference on Trade and Development. New York and Geneva, United Nations Publication pp. $143-172 \mathrm{http}: / /$ www.google.com/search?hl=en\&lr=lang_en\&ie=UTF-

8\&as_qdr=all\&q=Pros+and+Cons+of+EMV+card\&btnG=Search\&lr=lang_en accessed $23^{\text {rd }}$ July 2004.

35. VeriFone A division of Hewlett-Packard Company (2001) VeriFone Solutions http://www.verifone.com/pdf/emv_fact_sheet.pdf accessed $23^{\text {rd }}$ July 2004.

36. VeriFone Inc. (2003) EMV: Global Framework for Smart Card Payment http://www.verifone.com/ pdf/EMV_white_paper.pdf accessed $23^{\text {rd }}$ July 2004.

37. Visa Organization (2004) Visa Smart Card www.corporate.visa.com accessed $23^{\text {rd }}$ July 2004.

38. Won, J., Giesecke and Devrient (2003) Smart Card Technology Capabilities http://csrc.nist.gov/cardtechnology/presentations/current-capabilities/Jun-GD-NIST-CardTech2003.pdf accessed $1^{\text {st }}$ August 2004.

39. Worthington, S. (1996) Smart cards and retailers - Who stands to benefit? International Journal of Retail \& Distribution Management, Vol. 24 No. 9, pp. 27-34. 